\title{
Availability of $\mathrm{O}_{2}$ and $\mathrm{H}_{2} \mathrm{O}_{2}$ on Pre-Photosynthetic Earth
}

\author{
Jacob Haqq-Misra, James F. Kasting, ${ }^{2}$ and Sukyoung Lee ${ }^{1}$
}

\begin{abstract}
Old arguments that free $\mathrm{O}_{2}$ must have been available at Earth's surface prior to the origin of photosynthesis have been revived by a new study that shows that aerobic respiration can occur at dissolved oxygen concentrations much lower than had previously been thought, perhaps as low as $0.05 \mathrm{n} M$, which corresponds to a partial pressure for $\mathrm{O}_{2}$ of about $4 \times 10^{-8}$ bar. We used numerical models to study whether such $\mathrm{O}_{2}$ concentrations might have been provided by atmospheric photochemistry. Results show that disproportionation of $\mathrm{H}_{2} \mathrm{O}_{2}$ near the surface might have yielded enough $\mathrm{O}_{2}$ to satisfy this constraint. Alternatively, poleward transport of $\mathrm{O}_{2}$ from the equatorial stratosphere into the polar night region, followed by downward transport in the polar vortex, may have brought $\mathrm{O}_{2}$ directly to the surface. Thus, our calculations indicate that this "early respiration" hypothesis might be physically reasonable. Key Words: Early Earth-Oxygen-Respiration-Tracer transport-General circulation. Astrobiology 11, 293-302.
\end{abstract}

\section{Introduction}

$\mathrm{O}$ VER THE PAST 40 YEARS, both biologists (Schwartz and Dayhoff, 1978; Castresana et al., 1994; Pereira et al., 2001; Ducluzeau et al., 2008; Brochier-Armanet et al., 2009) and paleontologists (Cloud, 1972; Schopf, 1975; Towe, 1978, 1988, 1990,1996 ) have argued that free $\mathrm{O}_{2}$ must have been available, at least in small quantities, prior to the origin of oxygenic photosynthesis. These arguments have been considered highly speculative because free $\mathrm{O}_{2}$ is generally considered to have been absent near Earth's surface prior to the origin of oxygenic photosynthesis (Walker, 1977; Kasting, 1993). Indeed, significant amounts of free $\mathrm{O}_{2}$ did not appear in the atmosphere until about 2.4 Ga (Holland, 1994, 2006; Farquhar et al., 2000). Before this major rise of atmospheric oxygen, even photosynthetically produced $\mathrm{O}_{2}$ would have existed only locally within surface water and in short-lived plumes of gas that escaped into the otherwise anoxic atmosphere (Kasting, 1992; Pavlov et al., 2001).

The arguments that some free oxygen must have existed before photosynthesis are almost all biologically based. Cloud (1972) pointed out that early $\mathrm{O}_{2}$ producers would have needed chemical electron acceptors to protect themselves against the $\mathrm{O}_{2}$ they created. He suggested that ferrous iron in the early oceans could have provided such a sink. However, the $\mathrm{O}_{2}$ would have been produced internally within cells, whereas the ferrous iron was external, so it is not obvious that this solution would have worked. Schopf (1975) recognized this and suggested that early photosynthesizers must have had at least rudimentary mecha- nisms for coping with oxygen. Towe (1978, 1988, 1996) elaborated on this idea by examining the evolutionary history of specific enzymes for $\mathrm{O}_{2}$ protection, notably the superoxide dismutases, and arguing that they must have evolved at a very early stage.

Molecular phylogenists have added to the strength of these arguments over the years. Based on an early composite protein/rRNA evolutionary tree, Schwartz and Dayhoff (1978) reasoned that aerobic respiration must have preceded oxygenic photosynthesis because of its wide distribution among different organisms. Their analysis included genes for different cytochrome oxidases, which are key enzymes in aerobic metabolism. More recent studies (Castresana et al., 1994; Pereira et al., 2001; Ducluzeau et al., 2008; BrochierArmanet et al., 2009) have examined the history of cytochrome oxidases in increasing detail. The current consensus is that at least some members of this enzyme family had a monophyletic origin that preceded the origin of oxygenic photosynthesis. Nitric oxide reduction, that is, oxidation of organic matter using NO (the key step in denitrification), may also have been an early evolutionary invention (Castresana and Saraste, 1995). Whether aerobic respiration or nitric oxide reduction came first, and whether one of these metabolisms evolved from the other, remains unresolved (Hendriks et al., 2000; Pereira et al., 2001; Ducluzeau et al., 2008).

Now, a new study (Stolper et al., 2010) has shown that some modern aerobes can respire at extremely low $\mathrm{O}_{2}$ levels-much lower than previously thought. The prevailing wisdom has been that organisms switch from aerobic

Departments of ${ }^{1}$ Meteorology and ${ }^{2}$ Geosciences, The Pennsylvania State University, University Park, Pennsylvania. 
respiration to anaerobic forms of metabolism (primarily fermentation) below the Pasteur point of $\sim 0.01$ times the present atmospheric level of $\mathrm{O}_{2}$. The solubility of $\mathrm{O}_{2}$ in pure water at $25^{\circ} \mathrm{C}$ is $1.3 \times 10^{-3} \mathrm{~mol} / \mathrm{L} /$ bar (Sander, 2009), so this corresponds to a dissolved $\mathrm{O}_{2}$ concentration of $2.7 \mu \mathrm{M} .\left(\mathrm{O}_{2}\right.$ solubility in seawater is about $20 \%$ lower.) By contrast, the new study shows that the common bacterium E. coli can grow at dissolved $\mathrm{O}_{2}$ concentrations of $3 \mathrm{nM}$ or lower, or about 1000 times lower than previously believed. The new work was made possible by the development of $\mathrm{O}_{2}$-sensing electrodes that are accurate down to $3-5 \mathrm{nM}$ concentrations. (Note of caution: The observed lower limit for respiration in these studies is also the lower limit of accuracy for the electrodes. This suggests that additional confirmation of these results is needed.) A theoretical extrapolation to smaller organisms suggests that a primitive aerobe, only $0.5 \mu \mathrm{m}$ in diameter, might be able to respire at dissolved $\mathrm{O}_{2}$ concentrations of $0.05 \mathrm{nM}$ (Stolper et al., 2010). In terms of equivalent atmospheric partial pressure, this lower limit is equivalent to $\mathrm{pO}_{2}=4 \times 10^{-8}$ bar, or about $10^{-7}$ times the present atmospheric level. These limits are summarized in Table 1, where they are compared to calculated $\mathrm{O}_{2}$ and $\mathrm{H}_{2} \mathrm{O}_{2}$ sources that might have been available prior to the origin of photosynthesis. The calculations are described below.

Although we ourselves have previously argued that free $\mathrm{O}_{2}$ was scarce prior to the origin of oxygenic photosynthesis, the new work by Stolper et al. (2010) has prompted us to reexamine our assumptions. For example, photochemical models do indeed predict that some free $\mathrm{O}_{2}$, along with photochemically generated oxidants such as hydrogen peroxide $\left(\mathrm{H}_{2} \mathrm{O}_{2}\right)$ and sulfate $\left(\mathrm{SO}_{4}^{=}\right)$, should have been generated in small quantities (see, e.g., Kasting et al., 1984; McKay and Hartman, 1991; Liang et al., 2006; Segura et al., 2007). And much larger concentrations of free $\mathrm{O}_{2}$, up to $0.1 \%$ mixing

Table 1. Measured and Calculated Limits on Respiration and $\mathrm{O}_{2} / \mathrm{H}_{2} \mathrm{O}_{2}$ Availability

\begin{tabular}{|c|c|c|}
\hline Limit & {$\left[\mathrm{O}_{2}\right] n M^{*}$} & $\mathrm{pO}_{2}$ (bar) \\
\hline $\begin{array}{l}\text { Observed lower } \\
\text { growth limit }\end{array}$ & 3 & $2 \times 10^{-6}$ \\
\hline $\begin{array}{l}\text { Extrapolated lower } \\
\text { growth limit }\end{array}$ & 0.05 & $4 \times 10^{-8}$ \\
\hline $\begin{array}{l}\text { Average surface } \mathrm{O}_{2} \\
\quad \text { (2-bar } \mathrm{CO}_{2} \text { model) }\end{array}$ & $8 \times 10^{-6}$ & $6 \times 10^{-12}$ \\
\hline $\begin{array}{l}\text { Transient surface } \mathrm{O}_{2} \\
\text { (equinox model) }\end{array}$ & $7 \times 10^{-4}$ & $5 \times 10^{-10}$ \\
\hline $\begin{array}{l}\text { Transient surface } \mathrm{O}_{2} \\
\quad \text { (winter solstice model) }\end{array}$ & $3 \times 10^{-3}$ & $2 \times 10^{-9}$ \\
\hline $\begin{array}{l}\text { Maximum transient } \\
\text { surface } \mathrm{O}_{2}\end{array}$ & 4 & $3 \times 10^{-6}$ \\
\hline Limit & {$\left[\mathrm{H}_{2} \mathrm{O}_{2}\right] n M$} & $p \mathrm{H}_{2} \mathrm{O}_{2}$ (bar) \\
\hline $\begin{array}{l}\text { Average surface } \mathrm{H}_{2} \mathrm{O}_{2} \\
\text { (2-bar } \mathrm{CO}_{2} \text { model) }\end{array}$ & 0.16 & $2 \times 10^{-15}$ \\
\hline
\end{tabular}

Henry's Law constants at $25^{\circ} \mathrm{C}$ :

$\mathrm{O}_{2}: 1.3 \times 10^{-3} \mathrm{~mol} / \mathrm{L} / \mathrm{bar}$

$\mathrm{H}_{2} \mathrm{O}_{2}: 8.2 \times 10^{4} \mathrm{~mol} / \mathrm{L} / \mathrm{bar}$

${ }^{*} 1 \mathrm{n} M=10^{-9} \mathrm{~mol} / \mathrm{L}$.

†For $0.5 \mu$ m diameter cells (Stolper et al., 2010). ratio, should have existed at high altitudes, where it was produced by $\mathrm{CO}_{2}$ photolysis (Kasting et al., 1984; Liang et al., 2006; Segura et al., 2007). The question then is could any of this high-altitude $\mathrm{O}_{2}$ have made its way down to the surface before it was photochemically destroyed? Our modeling work addresses this question.

\section{Photochemical Production of $\mathrm{O}_{2}$ and $\mathrm{H}_{2} \mathrm{O}_{2}$}

Oxygen should have been produced abiotically in the sunlit portions of the early stratosphere. Following the atmospheric photochemistry explored by Kasting et al. (1979), Kasting and Walker (1981), and Kasting et al. (1984), the production of $\mathrm{O}_{2}$ in the stratosphere begins with the photolysis of $\mathrm{CO}_{2}$, which is by far the most abundant oxygenbearing species in these model atmospheres:

$$
\mathrm{CO}_{2}+h v \rightarrow \mathrm{CO}+\mathrm{O}
$$

Here, $v$ is frequency of the photon and $h$ is Planck's constant. The products of Reaction 1 then combine to form $\mathrm{O}_{2}$ :

$$
\mathrm{O}+\mathrm{O}+\mathrm{M} \rightarrow \mathrm{O}_{2}+\mathrm{M}
$$

where $\mathrm{M}$ is a third molecule, required to carry off the excess energy of the collision. $\mathrm{O}_{2}$ can also be produced in the troposphere by Reaction 1, along with

$$
\begin{gathered}
\mathrm{H}_{2} \mathrm{O}+h v \rightarrow \mathrm{H}+\mathrm{OH} \\
\mathrm{O}+\mathrm{OH} \rightarrow \mathrm{O}_{2}+\mathrm{H}
\end{gathered}
$$

Little of this $\mathrm{O}_{2}$ makes its way down to the surface, though, because it is destroyed almost immediately by reaction sequences such as

$$
\begin{aligned}
\mathrm{H}_{2} \mathrm{O}+h v & \rightarrow \mathrm{H}+\mathrm{OH} & (\times 2) \\
\mathrm{H}+\mathrm{O}_{2}+\mathrm{M} & \rightarrow \mathrm{HO}_{2}+\mathrm{M} & (\times 2) \\
\mathrm{H}_{2}+\mathrm{OH} & \rightarrow \mathrm{H}_{2} \mathrm{O}+\mathrm{H} & (\times 2) \\
\mathrm{HO}_{2}+\mathrm{H} & \rightarrow \mathrm{H}_{2} \mathrm{O}+\mathrm{O} & (\times 2) \\
\mathrm{O}+\mathrm{O}+\mathrm{M} & \rightarrow \mathrm{O}_{2}+\mathrm{M} & \\
\text { Net: } 2 \mathrm{H}_{2}+\mathrm{O}_{2} & \rightarrow 2 \mathrm{H}_{2} \mathrm{O} &
\end{aligned}
$$

along with

$$
\begin{aligned}
\mathrm{H}_{2} \mathrm{O}+h v & \rightarrow \mathrm{H}+\mathrm{OH} & (\times 2) \\
\mathrm{H}+\mathrm{O}_{2}+\mathrm{M} & \rightarrow \mathrm{HO}_{2}+\mathrm{M} & (\times 2) \\
\mathrm{CO}+\mathrm{OH} & \rightarrow \mathrm{CO}_{2}+\mathrm{H} & (\times 2) \\
\mathrm{HO}_{2}+\mathrm{H} & \rightarrow \mathrm{H}_{2} \mathrm{O}+\mathrm{O} & (\times 2) \\
\mathrm{O}+\mathrm{O}+\mathrm{M} & \rightarrow \mathrm{O}_{2}+\mathrm{M} & \\
\text { Net: } 2 \mathrm{CO}+\mathrm{O}_{2} & \rightarrow 2 \mathrm{CO}_{2} &
\end{aligned}
$$

The formyl radical, $\mathrm{HCO}$, also contributes to $\mathrm{O}_{2}$ destruction by the reactions

$$
\begin{aligned}
\mathrm{H}+\mathrm{CO}+\mathrm{M} & \rightarrow \mathrm{HCO}+\mathrm{M} \\
\mathrm{HCO}+\mathrm{O}_{2} & \rightarrow \mathrm{HO}_{2}+\mathrm{CO}
\end{aligned}
$$


Once converted to $\mathrm{HO}_{2}, \mathrm{O}_{2}$ can readily react with other species by reactions such as those shown in sequences (5) and (6). The net effect of this tropospheric photochemistry is to recombine $\mathrm{O}_{2}$ with $\mathrm{H}_{2}$ and $\mathrm{CO}$ through reactions that are catalyzed by the by-products of $\mathrm{H}_{2} \mathrm{O}$ photolysis.

Other reduced gases, $\mathrm{CH}_{4}$ for example, may also have served as $\mathrm{O}_{2}$ sinks on early Earth. $\mathrm{CH}_{4}$ should have become abundant once methanogens evolved (Walker, 1977; Kharecha et al., 2005). But $\mathrm{CH}_{4}$ would have been produced at the expense of $\mathrm{H}_{2}$ by the reaction

$$
\mathrm{CO}_{2}+4 \mathrm{H}_{2} \rightarrow \mathrm{CH}_{4}+2 \mathrm{H}_{2} \mathrm{O}
$$

Alternatively, $\mathrm{CH}_{4}$ could have been produced by fermentation of organic matter, followed by production of methane from by-products such as acetate. But much of this organic matter itself would presumably have been generated from $\mathrm{H}_{2}$-based anoxygenic photosynthesis (Kharecha et al., 2005). Thus, for our purposes here, it is sufficient to think of $\mathrm{H}_{2}$ as a surrogate for all such reduced gases.

Because of catalytic cycles such as (5) and (6), the $\mathrm{O}_{2}$ content of the early atmosphere would have depended inversely on the $\mathrm{H}_{2}$ and $\mathrm{CO}$ concentrations. The $\mathrm{H}_{2}$ mixing ratio of the early atmosphere should have been determined by the balance between volcanic outgassing and escape of hydrogen to space (Walker, 1977; Kasting and Catling, 2003) and is expected to have been of the order of 100-1000 ppmv for $\mathrm{H}_{2}$ outgassing rates of $(0.7-7) \times 10^{12} \mathrm{~mol} / \mathrm{yr}$. These outgassing rates bracket the range considered by Holland (2002) and Canfield et al. (2006).

\subsection{Model scenarios}

Vertical profiles of $\mathrm{O}_{2}$ in the early atmosphere have been calculated by a number of different authors (e.g., Kasting et al., 1979, 1984; Pavlov et al., 2001; Segura et al., 2007). We used the model of Segura et al. (2007) to calculate $\mathrm{O}_{2}$ mixing ratio profiles for three different atmospheric $\mathrm{CO}_{2}$ partial pressures: $0.02,0.2$, and 2 bar (Fig. 1). These choices of $\mathrm{pCO}_{2}$ are meant to span the range of plausible $\mathrm{CO}_{2}$ concentrations during the Late Hadean/Early Archean, 4.0-3.0 Ga. At the two lower $\mathrm{CO}_{2}$ concentrations, the atmospheric surface pressure was taken to be $1 \mathrm{bar}$, and the surface temperature was set equal to $278 \mathrm{~K}$. For the 0.2-bar atmosphere, that surface temperature would be appropriate for $4.0 \mathrm{Ga}$ and 75 percent of current solar luminosity (Kasting, 1990). The 0.02bar $\mathrm{CO}_{2}$ atmosphere would have needed help from other greenhouse gases to reach this surface temperature during this time period. For the 2-bar $\mathrm{CO}_{2}$ calculation, the surface pressure was taken to be 2.8 bar, and the surface temperature was set at $317 \mathrm{~K}$, which is again consistent with conditions at 4.0 Ga (Kasting, 1990). No new one-dimensional climate simulations were performed for this study. The eddy diffusion profile in the latter case was changed to be self-consistent with this warmer, thicker troposphere by increasing the vertical range over which high $\left(10^{5} \mathrm{~cm}^{2} \mathrm{~s}^{-1}\right)$ eddy coefficients applied (Kasting, 1990).

The hydrogen outgassing rate in each model was assumed to be $1 \times 10^{10} \mathrm{H}_{2}$ molecules $\mathrm{cm}^{-2} \mathrm{~s}^{-1}$, or about $2.7 \times 10^{12} \mathrm{~mol} /$ yr. This is close to the $\mathrm{H}_{2}$ outgassing rate $\left(2.4 \times 10^{12} \mathrm{~mol} / \mathrm{yr}\right)$ estimated by Holland (2009). This produced atmospheric $\mathrm{H}_{2}$ mixing ratios close to $300 \mathrm{ppmv}$ in all three cases. Some

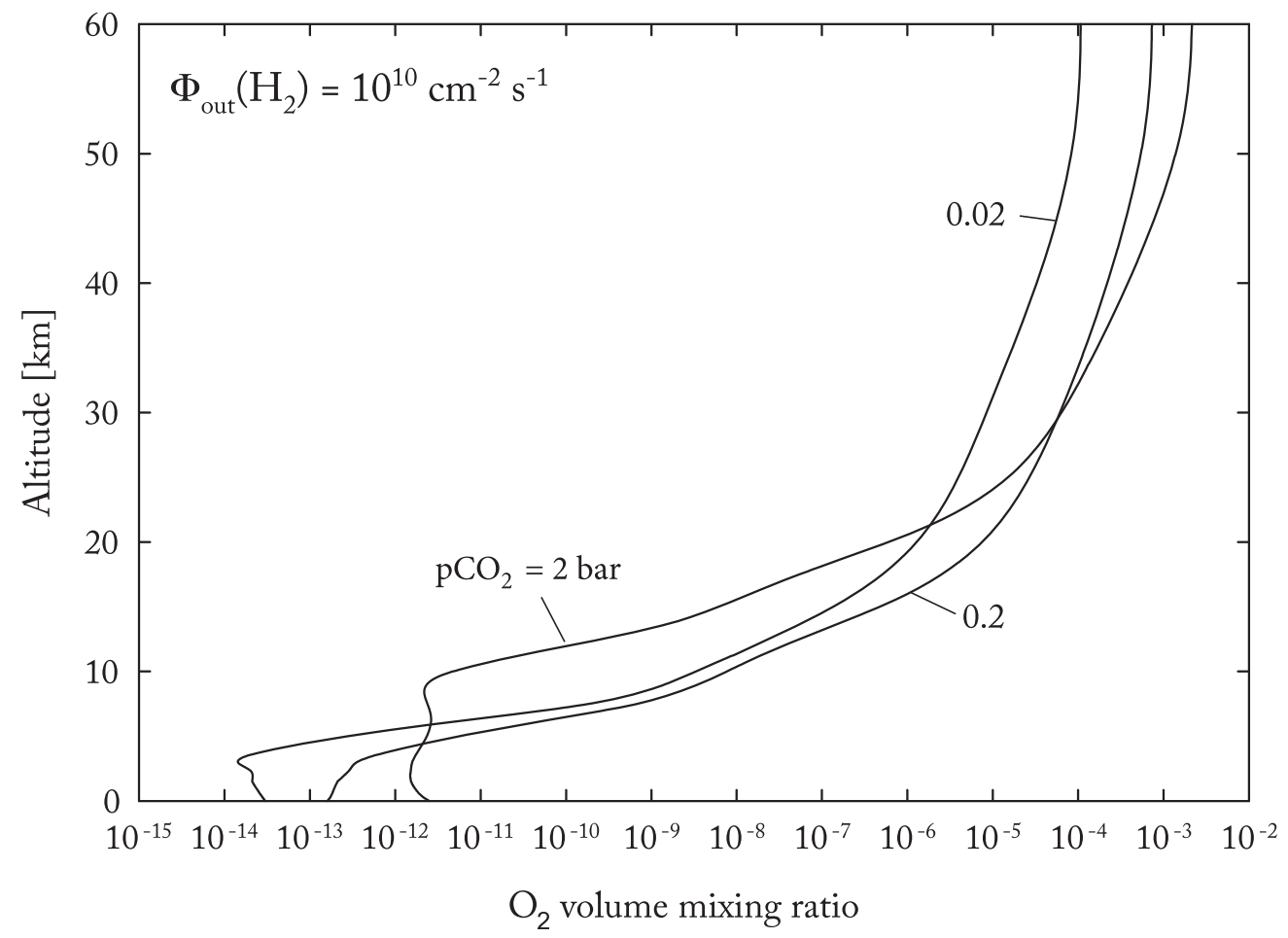

FIG. 1. Vertical profiles of $\mathrm{O}_{2}$ volume mixing ratio at $\mathrm{CO}_{2}$ partial pressures of $0.02,0.2$, and 2.0 bar. These profiles are calculated with a one-dimensional photochemical model with an $\mathrm{H}_{2}$ outgassing rate $\Phi_{\text {out }}\left(\mathrm{H}_{2}\right)=10^{10} \mathrm{~cm}^{-2} \mathrm{~s}^{-1}$. 
sensitivity studies, described below, were also performed with an outgassing rate that was 10 times smaller. $\mathrm{SO}_{2}$ outgassing was fixed at $3.5 \times 10^{8} \mathrm{~cm}^{-2} \mathrm{~s}^{-1}$, or $\sim 9.4 \times 10^{10} \mathrm{~mol} / \mathrm{yr}$, following Ono et al. (2003). CO outgassing (which is smaller than $\mathrm{H}_{2}$ outgassing) was neglected. $\mathrm{CH}_{4}$ was held to negligible values. $\mathrm{NO}$ was assumed to have been produced by lightning at a rate of $5.85 \times 10^{8} \mathrm{~cm}^{-2} \mathrm{~s}^{-1}$, or $\sim 1.6 \times 10^{11} \mathrm{~mol} /$ yr for the 0.2-bar $\mathrm{CO}_{2}$ case. $\mathrm{O}_{2}$ production was 2.5 times higher. All lightning production rates were scaled to a value of $2.7 \times 10^{11} \mathrm{~mol} \mathrm{NO} / \mathrm{yr}$ for modern Earth, which is slightly higher than the value of $2.1 \times 10^{11} \mathrm{~mol} / \mathrm{yr}$ estimated by Martin et al. (2002).

\subsection{Predicted $\mathrm{O}_{2}$ concentrations}

Figure 1 shows that the concentration of $\mathrm{O}_{2}$ in the model atmosphere increases with $\mathrm{pCO}_{2}$, as expected. The $\mathrm{O}_{2}$ mixing ratio in the stratosphere, near $50 \mathrm{~km}$, reaches a maximum of about $2 \times 10^{-3}$ in the high- $\mathrm{CO}_{2}$ case. This, of course, would be more than enough to sustain aerobic respiration were the same $\mathrm{O}_{2}$ concentration to exist at the surface. The $\mathrm{O}_{2}$ mixing ratio at the surface, however, is 9 orders of magnitude lower, about $2 \times 10^{-12}$, because it is being consumed by Reactions 5-9 above. Indeed, the little $\mathrm{O}_{2}$ that exists near the surface is sustained by lightning in this model, which breaks down $\mathrm{CO}_{2}$ according to

$$
2 \mathrm{CO}_{2} \rightarrow 2 \mathrm{CO}+\mathrm{O}_{2}
$$

But this surface $\mathrm{O}_{2}$ concentration is still far too low to sustain respiration, even in the most optimistic case defined by Stolper et al. (2010). Given that the total surface pressure is 2.8 bar in this model, $\mathrm{pO}_{2}$ near the surface is $\sim 6 \times 10^{-12}$ bar.
This is still almost 4 orders of magnitude lower than the limit for respiration (Table 1).

\subsection{Production of $\mathrm{H}_{2} \mathrm{O}_{2}$}

A second photochemically produced oxidant that has received previous attention (Kasting et al., 1984; McKay and Hartman, 1991; Liang et al., 2006) is hydrogen peroxide, $\mathrm{H}_{2} \mathrm{O}_{2} \cdot \mathrm{H}_{2} \mathrm{O}_{2}$ is produced from the by-products of $\mathrm{H}_{2} \mathrm{O}$ photolysis,

$$
\mathrm{OH}+\mathrm{OH}+\mathrm{M} \rightarrow \mathrm{H}_{2} \mathrm{O}_{2}+\mathrm{M}
$$

which can yield $\mathrm{O}_{2}$ by the disproportionation reaction

$$
2 \mathrm{H}_{2} \mathrm{O}_{2} \rightarrow 2 \mathrm{H}_{2} \mathrm{O}+\mathrm{O}_{2}
$$

This type of reaction is slow in the gas phase but could be catalyzed in solution by contact with mineral surfaces. Concentrations of $\mathrm{H}_{2} \mathrm{O}_{2}$ in the troposphere are also very low for the three cases studied (Fig. 2); however, the solubility of $\mathrm{H}_{2} \mathrm{O}_{2}$ is much higher than that of $\mathrm{O}_{2}$, about $8.2 \times 10^{4} \mathrm{~mol} / \mathrm{L} /$ bar at $25^{\circ} \mathrm{C}$ (Sander, 2009). For the 2-bar $\mathrm{CO}_{2}$ case, the predicted partial pressure of $\mathrm{H}_{2} \mathrm{O}_{2}$ at the surface is about $2 \times 10^{-15}$ bar, so the dissolved $\mathrm{H}_{2} \mathrm{O}_{2}$ concentration is $1.6 \times 10^{-10} \mathrm{~mol} / \mathrm{L}$. A similar ground-level $\mathrm{H}_{2} \mathrm{O}_{2}$ partial pressure is obtained for the 0.2 -bar $\mathrm{CO}_{2}$ case if the $\mathrm{H}_{2}$ outgassing rate is divided by 10 (which remains within the plausible range of outgassing rates). Dividing by 2 to account for the stoichiometry of Reaction 13 gives an equivalent dissolved $\mathrm{O}_{2}$ concentration of $0.08 \mathrm{nM}$, just above the lower limit for respiration extrapolated by Stolper et al. (2010) for small cells. So, if their calculated threshold is correct, and if $\mathrm{H}_{2} \mathrm{O}_{2}$ was

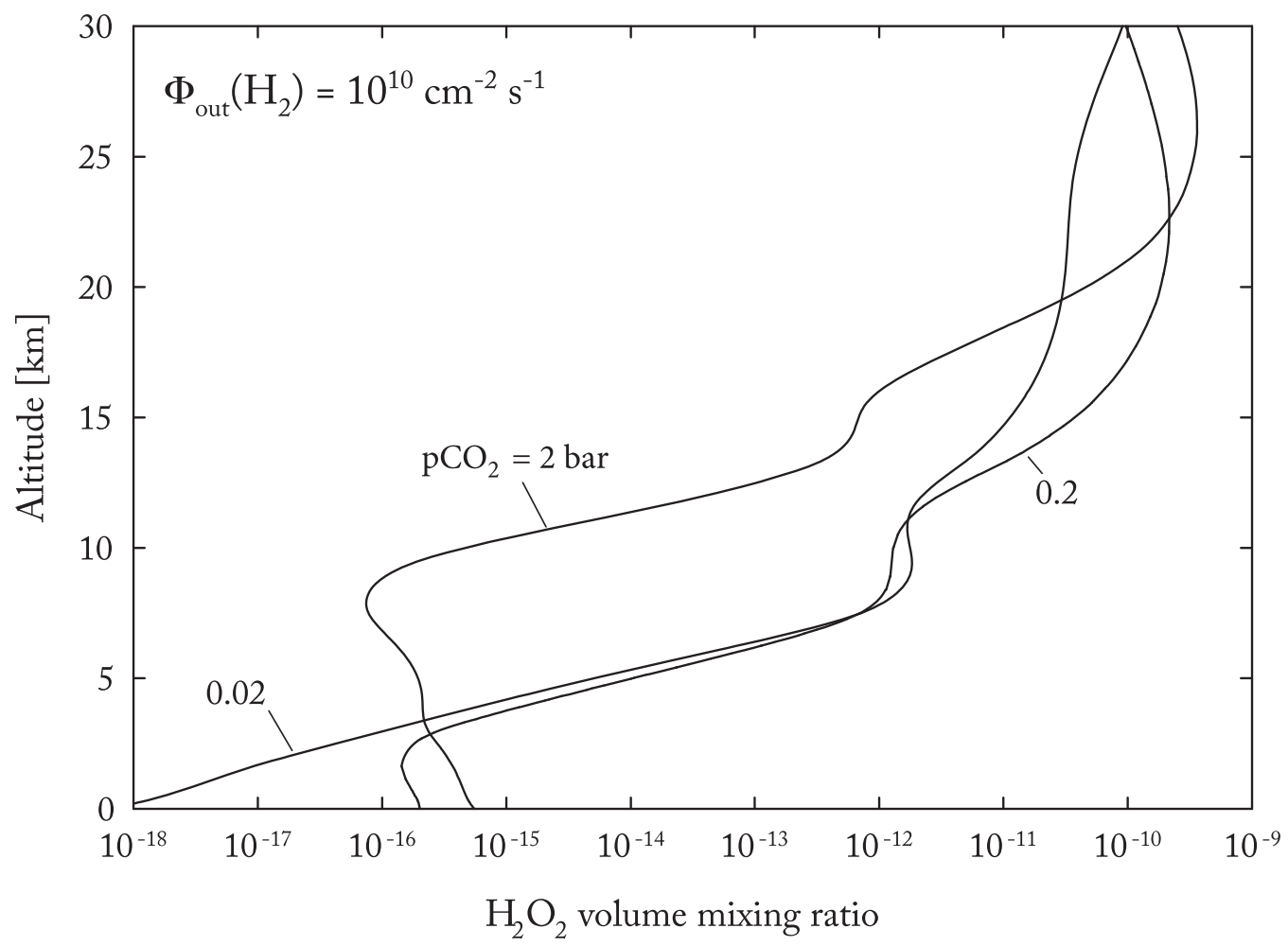

FIG. 2. Vertical profiles of $\mathrm{H}_{2} \mathrm{O}_{2}$ volume mixing ratio for the three model atmospheres shown in Fig. 1 . 
converted to $\mathrm{O}_{2}$ and taken up by organisms before it could react with something else, then this is a possible mechanism for fueling aerobic respiration prior to the invention of oxygenic photosynthesis.

We should note that McKay and Hartman (1991) put forward a hypothesis similar to the one presented here, that is, they argued that the presence of photochemically produced $\mathrm{H}_{2} \mathrm{O}_{2}$ allowed early organisms to develop defenses against oxygen toxicity. They used numbers from a photochemical model study by Kasting et al. (1985). The quoted flux of $\mathrm{H}_{2} \mathrm{O}_{2}$ to the surface was $\sim 10^{10} \mathrm{~cm}^{-2} \mathrm{~s}^{-1}$, and the maximum dissolved $\mathrm{H}_{2} \mathrm{O}_{2}$ concentration in surface water, as calculated from a simple box model, was $5 \times 10^{-8} \mathrm{~mol} / \mathrm{L}$. That value is about 300 times higher than the one estimated here. But the Kasting et al. (1985) model was designed to simulate relatively oxygenated, Proterozoic atmospheres, not the anoxic Archean atmospheres considered here. Our calculated $\mathrm{H}_{2} \mathrm{O}_{2}$ surface flux (mostly from $\mathrm{H}_{2} \mathrm{O}_{2}$ dissolved in rainwater) in the present 0.2 -bar $\mathrm{CO}_{2}$ model is of the order of $10^{6} \mathrm{~cm}^{-2} \mathrm{~s}^{-1}$, which is about $10^{4}$ times less than estimated by McKay and Hartman. With our more modest numbers, $\mathrm{H}_{2} \mathrm{O}_{2}$ appears to be just marginally capable of fueling early respiration.

\section{Transport of $\mathrm{O}_{2}$ by the Brewer-Dobson Circulation}

An alternative way of getting $\mathrm{O}_{2}$ to the surface would be to transport it downwards from the stratosphere in the polar night region where it was protected against photochemical destruction. The calculations shown in Figs. 1 and 2 cannot account for this mechanism because our one-dimensional photochemical model assumes global average conditions, with the sun always shining. $\mathrm{O}_{2}$ is destroyed within seconds or minutes when it reaches the troposphere in the presence of ultraviolet (UV) photons. In the real, modern atmosphere, ozone $\left(\mathrm{O}_{3}\right)$ is produced photochemically in the stratosphere and is transported poleward and downward by the Brewer-Dobson circulation (Brewer, 1949; Holton et al., 1995; Callaghan and Salby, 2002; Austin and Li, 2006). This suggests a mechanism by which photochemically produced $\mathrm{O}_{2}$ could have been transported to the surface of early Earth.

Exchange of air between the stratosphere and troposphere then occurs through a variety of processes, most of which are dominant in regions outside the tropics. In the absence of physical features (such as topography), some mass exchange occurs by diffusion, while some occurs by a mechanism known as "tropopause folding" (Reed, 1955; Danielsen, 1968; Shapiro, 1980; Wei, 1987; Lamarque and Hess, 1994). Although the time-mean tropopause is approximately symmetric about the equator, tropopause structure in regions with large vertical shear and strong meridional temperature gradients can fold and thereby transport stratospheric air downward (Holton et al., 1995). Such events commonly occur in conjunction with cyclogenesis (i.e., the development of low-pressure circulation systems in the atmosphere). Part of this transport is also described by the influence of breaking waves above the tropopause according to the downward control principle (Haynes et al., 1991). Topographic features also play an important role in troposphere-stratosphere exchange by generating planetary-scale waves that propagate into the stratosphere and then break to induce the mixing of air (McIntyre and Palmer, 1983; Randel et al., 1993). Finally, the stratosphere in the winter hemisphere cools because of the strong equator-to-pole temperature gradient, which intensifies the Brewer-Dobson circulation and causes the formation of a polar vortex. Air that flows from the stratosphere through the polar vortex can mix with air in the troposphere either directly (Bowman, 1993; Mizuta and Yoden, 2001) or from the interaction of planetary waves with the vortex (Waugh, 1993).

\subsection{Three-dimensional (3-D) tracer model}

We investigated the downward transport of stratospheric oxygen by modeling $\mathrm{O}_{2}$ as a passive atmospheric tracer in an idealized atmospheric general circulation model (GCM). Our GCM was described by Frierson et al. (2006) and Haqq-Misra (2010) and includes a spectral dynamical core (with T42 resolution), gray radiative transfer, latent heat release, and a diffusive boundary layer scheme. This provides a way to estimate the amount of stratospheric $\mathrm{O}_{2}$ that could reach the surface without the need for an elaborate coupled climatechemistry model, which would be a far more demanding computational task. Here, we conceptually account for the photochemical loss of $\mathrm{O}_{2}$ in the troposphere; however, our model contains no actual atmospheric chemistry and should be considered only as a proof of concept for downward oxygen transport on early Earth. We note that surface oxygen does not need to be well mixed because early respiring organisms may have thrived in oxygen oases that only covered a fraction of the surface.

We represent $\mathrm{O}_{2}$ as a passive tracer that follows the flow determined in our model by solving an advection-diffusion equation. We release this passive tracer instantaneously into the stratosphere of a GCM configuration that has already reached a statistically steady state. By doing so, we simulate photochemical production of $\mathrm{O}_{2}$ at a single moment in time so that we can observe the amount of tracer that reaches the surface.

Our tracer $\xi=\xi(t, p, \phi, \lambda)$ is a function of time $t$, pressure $p$, latitude $\phi$, and longitude $\lambda$. It is given an initial distribution centered on the equator with the form

$$
\begin{aligned}
& \xi(0, p, \phi, \lambda)= \\
& \begin{cases}\xi_{0} & \text { for } 90^{\circ} \mathrm{S} \leq \phi \leq 60^{\circ} \mathrm{N} \text { and } 5 \mathrm{hPa} \leq p \leq 35 \mathrm{hPa} \\
0 & \text { otherwise }\end{cases}
\end{aligned}
$$

In terms of altitude, the tracer release area corresponds to a range of about $21-28 \mathrm{~km}$ in the modern atmosphere. We set the unitless tracer concentration to a constant value $\xi_{0}$ in this region. Because we specify no other sources or sinks of $\xi$, we do not include reaction rates for $\mathrm{O}_{2}$ production and destruction. However, a low-oxygen early Earth atmosphere would be susceptible to $\mathrm{O}_{2}$ loss from water vapor photolysis in the troposphere, so any stratospherically produced $\mathrm{O}_{2}$ that is transported to the surface will therefore have a lifetime limited by its exposure to sunlight. The longest residence time of such an $\mathrm{O}_{2}$ molecule would occur in the polar night, where some regions reside in perpetual darkness for up to 6 months. UV photons would be absent or scarce during this season and allow $\mathrm{O}_{2}$ to accumulate. In the summertime, though, we assume that $\mathrm{O}_{2}$ could not accumulate in the troposphere because it would be destroyed in the presence of direct sunlight. Thus, we only model the concentration of $\xi$ over a period of 180 
days when loss of $\mathrm{O}_{2}$ would be minimal. Shielding by organic haze could conceivably extend the region where downwelling $\mathrm{O}_{2}$ might survive in the troposphere (Pavlov et al., 2001; Wolf and Toon, 2010); however, examining this possibility would require a more elaborate model.

Transport of stratospheric tracer to the surface was explored under eight different climate conditions in order to examine the various processes that contribute to stratosphere-troposphere mass exchange. [See Haqq-Misra (2010) for detailed descriptions of these eight climate states.] The first two states consider idealized dry and moist circulations (which we refer to as dry 3-D and moist 3-D) that approximate the structure of the observed atmosphere. In these cases, exchange of tracer between the stratosphere and troposphere occurs through diffusion across the tropopause as well as tropopause folding events generated by baroclinically unstable waves. We next add realistic topographic data to dry 3-D and moist 3-D to generate planetary waves that can propagate into the stratosphere and strengthen the BrewerDobson circulation to increase tracer transport. (Realistic mountains and land-water masks are generated by interpolating from a one-sixth degree U.S. Navy mean topography and percent water data set. These data are limited to changes in surface geopotential height only and do not include soil temperature, moisture, or other surface properties.) Transport in the winter hemisphere is also enhanced by a stronger Brewer-Dobson circulation and accompanies the formation of a polar night vortex, so we add a seasonal cycle to the model to calculate dry and moist 3-D states with seasons. Finally, we combine these mechanisms to calculate dry 3-D and moist 3-D states that include both topography and seasons in order to maximize the downward transport of tracer.

\subsection{Tracer model results}

Initially, we performed calculations for models that lacked a seasonal cycle. The tracer $\xi$ was released into the strato- sphere at some initial time, $t_{0}$, and its subsequent evolution was followed for 180 model days. At this point, we calculated the fraction of tracer, $\xi / \xi_{0}$, that had reached the surface. Our calculations show that tracer transport in the dry 3-D case is greater than in moist 3-D because poleward transport by the stratospheric Brewer-Dobson circulation is stronger in the absence of moisture. (In general, meridional circulations are weaker in moist atmospheres because the condensation of water vapor in ascending air causes a decrease in the lapse rate-the vertical rate of cooling-so that air parcels rise more slowly.) This produces a maximum polar tracer abundance of $\xi / \xi_{0} \approx 3 \times 10^{-6}$ for dry 3 -D and $\xi / \xi_{0} \approx 2 \times 10^{-6}$ for moist 3-D. When we include realistic topography, planetary waves are generated that propagate into the stratosphere and provide a modest increase in surface tracer. Here, we find that our dry and moist simulations with topography give us maximum polar tracer abundances of $\xi / \xi_{0} \approx 9 \times 10^{-6}$ and $\xi / \xi_{0} \approx 5 \times 10^{-6}$, respectively.

The more interesting, and more realistic, cases are those in which a seasonal cycle is included. The seasonal cycle enhances downward transport by inciting a polar vortex in the winter hemisphere and also provides a region of darkness in which downwelling stratospheric $\mathrm{O}_{2}$ might survive. The most efficient downward transport occurs when both topography and seasons are included, because in this case topographic planetary waves are generated in the winter hemisphere where surface westerly winds are strong. Results from two initial simulations with a dry model atmosphere are shown in Fig. 3. In the left-hand panel, the simulation begins at northern autumnal equinox, while the right-hand panel shows a simulation that began at northern winter solstice. The two panels show relative tracer abundance $\xi / \xi_{0}$ at the surface after 180 days of evolution. In both cases, the tracer tends to accumulate toward the equator, but our winter solstice case shows an increase of about a factor of 10 in surface tracer abundance at the northern pole.
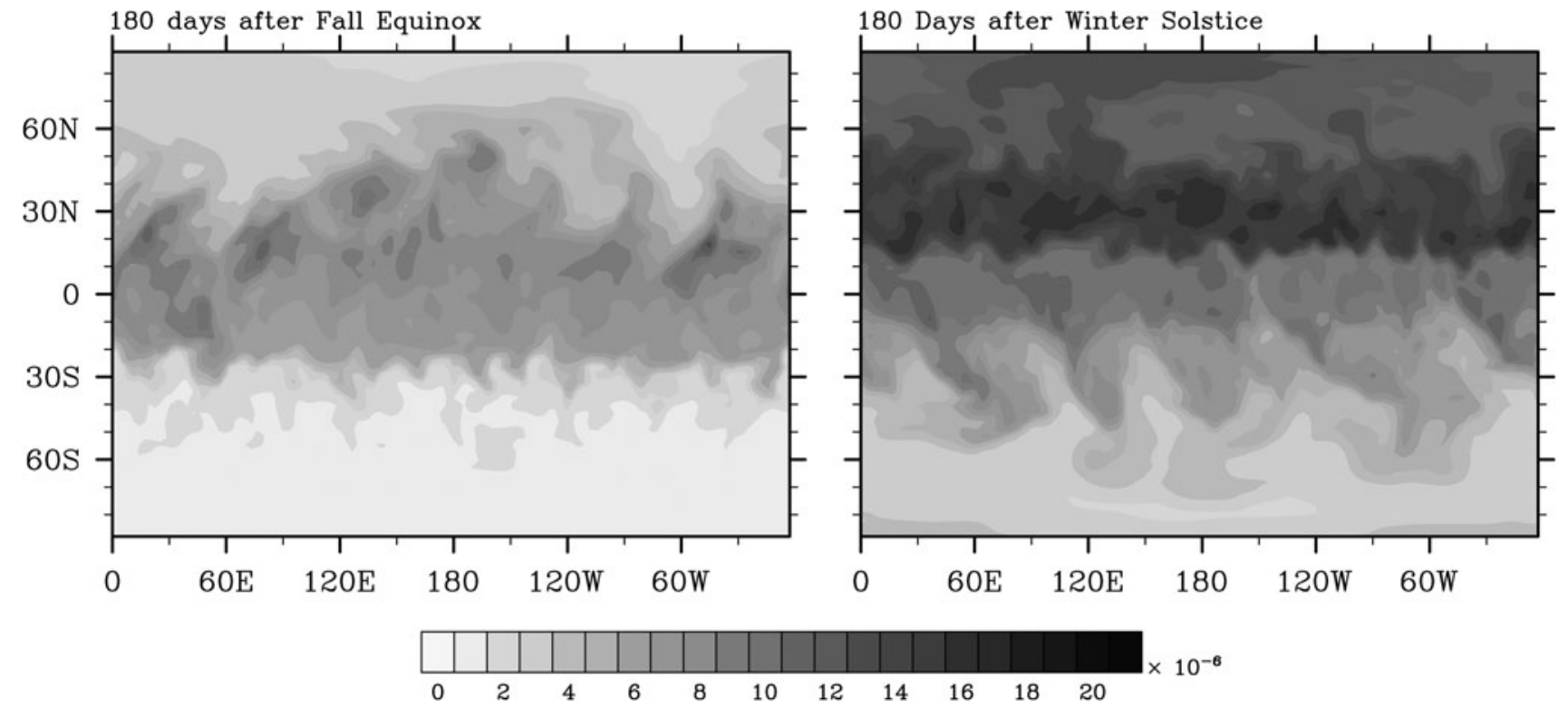

FIG. 3. Fraction of tracer $\xi / \xi_{0}$ at the surface 180 days after northern autumnal equinox (left panel) and northern winter solstice (right panel). Both simulations assume dry conditions and include topography. 
We first consider the results for the equinox simulation (left-hand panel). This simulation may be the most applicable to our $\mathrm{O}_{2}$ transport problem, because the North Pole would remain shaded throughout the calculation. In this case, the maximum tracer abundance in the northern polar region is about $\xi / \xi_{0} \approx 5 \times 10^{-6}$. To calculate a surface $\mathrm{O}_{2}$ concentration, this number must be multiplied by the $\mathrm{O}_{2}$ mixing ratio at the height at which the tracer was released, roughly $20-30 \mathrm{~km}$. According to Fig. 1, the $\mathrm{O}_{2}$ mixing ratio at these altitudes is about $10^{-4}$ for both the 0.2-bar and 2-bar $\mathrm{CO}_{2}$ simulations. Hence, the calculated ground-level $\mathrm{O}_{2}$ partial pressure is about $5 \times 10^{-10}$ bar. (This number should correspond to the 0.2-bar $\mathrm{CO}_{2}$ case, as the dynamical transport calculation is not valid for atmospheres with surface pressures greater than 1 bar.) This $\mathrm{pO}_{2}$ value is about 1000 times greater than the average surface $\mathrm{pO}_{2}$ calculated for the 0.2-bar $\mathrm{CO}_{2}$ case (Fig. 1), but it remains a factor of 100 lower than the lowest limit for respiration estimated by Stolper et al. (2010; see Table 1). So we see that this particular simulation does not succeed in explaining the early appearance of respiration.

These results may be overly pessimistic, however. The simulation that begins at winter solstice predicts highlatitude tracer levels that are about 4 times higher, $\xi$ / $\xi_{0} \approx 2 \times 10^{-5}$ (Fig. 3, right-hand panel). Furthermore, tracer transport in our model can be shown to depend on spatial (spectral) resolution. When we doubled the spectral resolution of our winter solstice model (to T85), the relative tracer abundance increased locally to as much as $3 \times 10^{-4}$ (Fig. 4).
The largest accumulations occurred near large mountain ranges such as the Himalayan and Rocky mountains. The reason for this accumulation can be understood in terms of the mechanism of Taylor columns (e.g., Hogg, 1973; Huppert, 1975). Much of this tracer occupies a region over land, where it could not dissolve into seawater, but some of it extends into the Bay of Bengal, the Arabian Sea, and perhaps even the Great Salt Lake. Of course, we do not know what topographic features were present on early Earth, but it appears that large mountain ranges can cause surface tracer to accumulate to concentrations from 10 to 50 times greater than the average hemispheric abundance. If these mountain ranges existed in the polar regions where $\mathrm{O}_{2}$ could have been protected from sunlight, then lakes or seas within these regions might have been exposed to relatively high surface $\mathrm{O}_{2}$ concentrations.

Abundances of $\mathrm{O}_{2}$ in the stratosphere may also be underestimated in the above calculations. The $\mathrm{O}_{2}$ mixing ratio continues to increase above $30 \mathrm{~km}$ in all our photochemical simulations, reaching values as high as $2 \times 10^{-3}$ in the 2 -bar $\mathrm{CO}_{2}$ case (Fig. 1). Stratospheric $\mathrm{O}_{2}$ could have been enhanced by another factor of 3 or more by the increased UV flux from the young Sun (Segura et al., 2007). (The calculations shown here assume present-day solar UV fluxes.) If our tracer model had extended higher into the stratosphere, some of this higher- $\mathrm{O}_{2}$ air may have been brought down to the surface as well. An approximate upper limit on surface $\mathrm{O}_{2}$ can be estimated by multiplying the maximum surface tracer

180 Days after Winter Solstice, T85
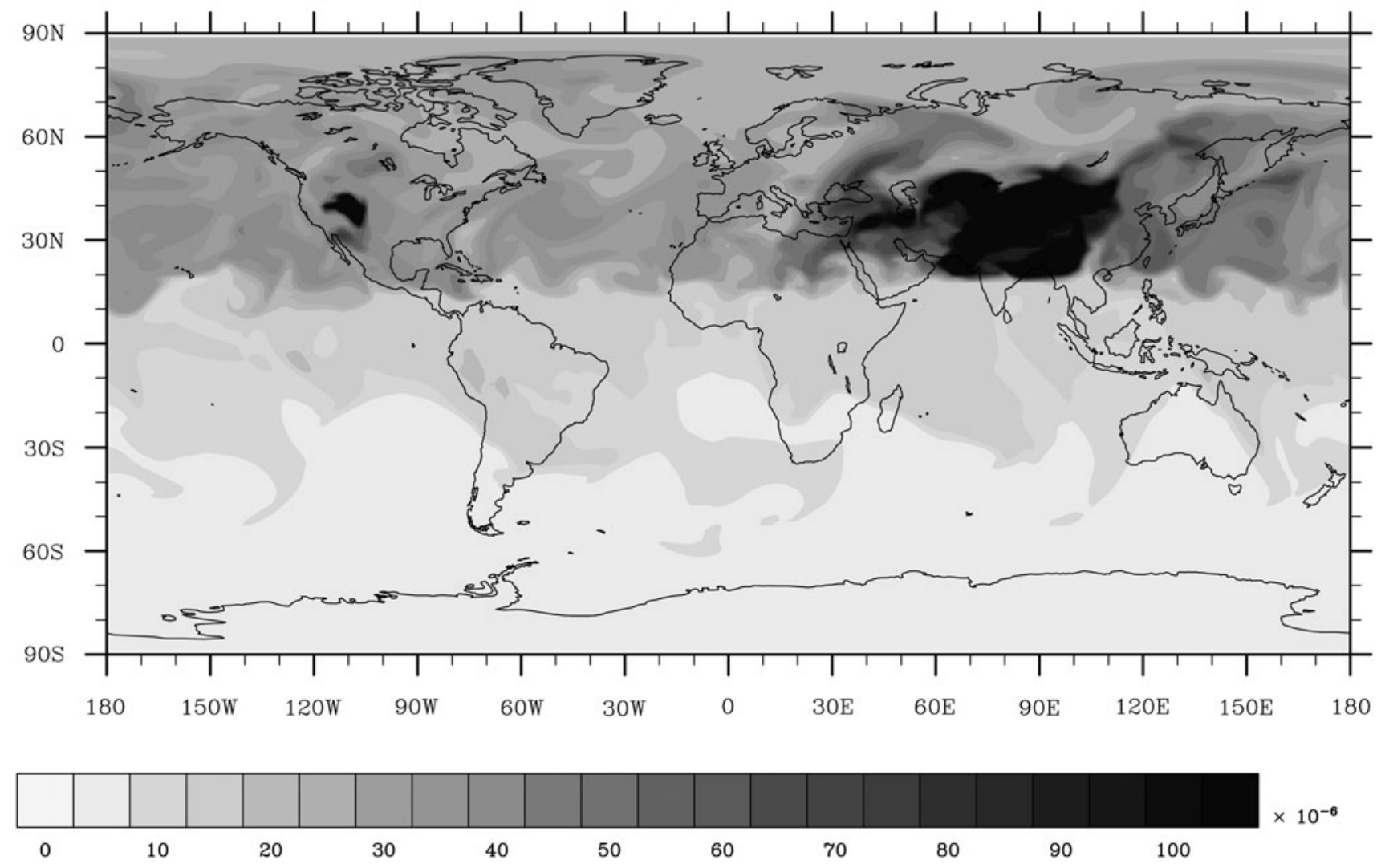

FIG. 4. Fraction of tracer $\xi / \xi_{0}$ at the surface 180 days after northern winter solstice under dry conditions with doubled spectral resolution. 
abundance from our transport model, $3 \times 10^{-4}$, by the $\mathrm{O}_{2}$ concentration at $50 \mathrm{~km}$ in the 2-bar $\mathrm{CO}_{2}$, high-UV case from Segura et al. (2007), $\sim 10^{-2}$. This yields a surface $\mathrm{pO}_{2}$ value of $3 \times 10^{-6}$ bar and a corresponding dissolved $\mathrm{O}_{2}$ concentration of $4 \mathrm{nM}$. The latter value exceeds the observed threshold for aerobic growth in E. coli (Stolper et al., 2010). Although this upper limit is admittedly optimistic, it demonstrates that this mechanism might also have allowed aerobic organisms to evolve in an otherwise anoxic world.

Further discussion should be added to the above calculations because of the uncertain conditions of early Earth. In particular, planetary formation models predict that younger planets rotate faster, and it has been suggested that early Earth rotated with a day as short as 14 to 18 hours (e.g., Walker and Zahnle, 1986; Williams, 2000). Because the vertical penetration depth of the overturning circulation is proportional to rotation rate (Hoskins et al., 1985), a faster rotator will be more effective at downward transport. As a result, downward transport may be somewhat enhanced on a rapidly rotating planet. Additionally, deviations in the axial tilt of Earth would change the latitudinal distribution of sunlight so that the wintertime Brewer-Dobson circulation strengthens as obliquity increases and weakens as obliquity decreases. The continental configuration of early Earth is also unknown, which means that topographically generated planetary waves could have been more active or less active in the past, depending on the size and position of the continents. For all three of these parameters, we have chosen present-day Earth values because of the uncertainty in the conditions of early Earth. Our model calculations can therefore be understood as a demonstration of an atmospheric transport mechanism that can be scaled appropriately as we continue to learn about the early history of Earth.

\section{Discussion}

All the "successful" simulations for delivery of either $\mathrm{O}_{2}$ or $\mathrm{H}_{2} \mathrm{O}_{2}$ to Earth's surface require high- $\mathrm{CO}_{2}$ early atmospheres. This is because high $\mathrm{CO}_{2}$ concentrations lead to greater production of $\mathrm{O}_{2}$ in the stratosphere from photolysis (Reactions 1 and 2). Additionally, high $\mathrm{CO}_{2}$ creates a warmer atmosphere by way of its greenhouse effect, which increases the concentrations of $\mathrm{H}_{2} \mathrm{O}$ and its photolysis by-product, $\mathrm{OH}$, that is instrumental in forming $\mathrm{H}_{2} \mathrm{O}_{2}$ (Reaction 11).

Recently published estimates of paleo- $\mathrm{CO}_{2}$ concentration, however, suggest that it may have been very low. Rosing et al. (2010) estimated an upper limit of $1 \times 10^{-3}$ bar, or 3 times the present atmospheric level, based on an analysis of banded iron formations. According to these authors, $\mathrm{CO}_{2}$ partial pressures higher than this value would have caused all the magnetite to be quantitatively converted to siderite, and this of course is not observed. If Rosing et al. are correct, then $\mathrm{CO}_{2}$ concentrations must have been low during the entire time between 1.8 and $3.8 \mathrm{Ga}$ when banded iron formations are known to have formed. However, the Rosing et al. (2010) paper is controversial, and several critical comments (not yet published) have been submitted regarding their conclusions. We hypothesize that conversion of magnetite to siderite was limited by the supply of organic matter, not by atmospheric or dissolved $\mathrm{CO}_{2}$. Support for this hypothesis is provided by the presence of isotopically light carbon in the siderite, which indicates that organic matter was involved in its formation (Becker and Clayton, 1972; Heimann et al., 2010). So, this particular argument for low $\mathrm{CO}_{2}$ does not appear to be valid.

Other published estimates for $\mathrm{pCO}_{2}$ in the Archean are also much lower than we require here. Rye et al. (1995) estimated that $\mathrm{pCO}_{2}$ was less than 0.03 bar at $2.8 \mathrm{Ga}$, based on an analysis of paleosols. Their estimate, however, has been criticized by Sheldon (2006). Sheldon argued that the thermodynamic data they used were out of date and that if their analysis were repeated it would predict $\mathrm{pCO}_{2}$ values lower than today, which is not at all consistent with the need for higher greenhouse warming in the past (Kasting, 1987; von Paris et al., 2008). Sheldon's own analysis of paleosols also led to low values, $\sim 0.008$ bar, but this estimate applies to the time around 2.2 Ga. Furthermore, his analysis assumed that every $\mathrm{CO}_{2}$ molecule that enters the soil reacts with silicate minerals. If this is not true, then atmospheric $\mathrm{CO}_{2}$ partial pressures could have been much higher than he calculated. Thus, there is nothing to preclude high $\mathrm{CO}_{2}$ concentrations during the early to mid-Archean, which is presumably when respiration first evolved.

Theoreticians have made different predictions for $\mathrm{CO}_{2}$ partial pressures on early Earth, with Walker (1985) favoring values as high as 10 bar prior to the origin of the continents and Sleep and Zahnle (2001) favoring values not much higher than today. We favor $\mathrm{pCO}_{2}$ values $\geq 0.2$ bar prior to the origin of methanogenesis, as this is approximately the amount of $\mathrm{CO}_{2}$ that was needed to keep the surface from freezing in the absence of additional greenhouse warming from $\mathrm{CH}_{4}$ (Kasting, 1987; Haqq-Misra et al., 2008). So, we consider the $\mathrm{CO}_{2}$ partial pressures assumed here to be plausible for the time period we are considering.

\section{Conclusions}

Trace amounts of oxidants, including free $\mathrm{O}_{2}$ and $\mathrm{H}_{2} \mathrm{O}_{2}$, could have been supplied to organisms living on Earth's surface prior to the origin of oxygenic photosynthesis. If the threshold for aerobic respiration $\left(0.05 \mathrm{n} M\right.$ dissolved $\left.\mathrm{O}_{2}\right)$ estimated by Stolper et al. (2010) is correct, then these trace oxidant levels might have permitted the early evolution of respiration. Production of both $\mathrm{O}_{2}$ and $\mathrm{H}_{2} \mathrm{O}_{2}$ is enhanced in warm, dense atmospheres that are rich in $\mathrm{CO}_{2}$.

Although the availability of $\mathrm{H}_{2} \mathrm{O}_{2}$ at the surface is reasonably well estimated by the models employed here, the problem of stratospheric $\mathrm{O}_{2}$ delivery deserves more detailed treatment. A fully coupled chemistry-climate GCM would allow for a more robust treatment of this problem by providing accurate temporal and spatial variations in $\mathrm{O}_{2}$ concentration and by allowing the inclusion of phenomena such as the presence of UV-screening organic haze.

\section{Acknowledgments}

We are grateful to Steven Feldstein for numerous discussions and insights regarding atmospheric dynamics and troposphere-stratosphere exchange. We also thank two anonymous reviewers for several suggestions that helped to strengthen this paper.

\section{Author Disclosure Statement}

No competing financial interests exist. 


\section{Abbreviation}

GCM, general circulation model.

\section{References}

Austin, J. and Li, F. (2006) On the relationship between the strength of the Brewer-Dobson circulation and the age of stratospheric air. Geophys Res Lett 33, doi:10.1029/ 2006 GL026867.

Becker, R.H. and Clayton, R.N. (1972) Carbon isotopic evidence for origin of a banded iron-formation in Western Australia. Geochim Cosmochim Acta 36:577-595.

Bowman, K.P. (1993) Large-scale isentropic mixing properties of the Antarctic polar vortex from analyzed winds. J Geophys Res 98:13-23.

Brewer, A.W. (1949) Evidence for a world circulation provided by the measurements of helium and water vapour distribution in the stratosphere. Quarterly Journal of the Royal Meteorological Society 75:351-363.

Brochier-Armanet, C., Talla, E., and Gribaldo, S. (2009) The multiple evolutionary histories of dioxygen reductases: implications for the origin and evolution of aerobic respiration. Mol Biol Evol 26:285-297.

Callaghan, P.F. and Salby, M.L. (2002) Three-dimensionality and forcing of the Brewer-Dobson circulation. Journal of the Atmospheric Sciences 59:976-991.

Canfield, D.E., Rosing, M.T., and Bjerrum, C. (2006) Early anaerobic metabolisms. Philos Trans $R$ Soc Lond B Biol Sci 361: 1819-1836.

Castresana, J. and Saraste, M. (1995) Evolution of energetic metabolism: The respiration-early hypothesis. Trends Biochem Sci 20:443-448.

Castresana, J., Lübben, M., Saraste, M., and Higgins, D.G. (1994) Evolution of cytochrome oxidase, an enzyme older than atmospheric oxygen. EMBO J 13:2516-2525.

Cloud, P.E. (1972) A working model of the primitive Earth. Am J Sci 272:537-548.

Danielsen, E.F. (1968) Stratospheric-tropospheric exchange based on radioactivity, ozone and potential vorticity. Journal of the Atmospheric Sciences 25:502-518.

Ducluzeau, A.L., Ouchane, S., and Nitschke, W. (2008) The $\mathrm{cbb}_{3}$ oxidases are an ancient innovation of the domain Bacteria. $\mathrm{Mol}$ Biol Evol 25:1158-1166.

Farquhar, J., Bao, H.M., and Thiemens, M. (2000) Atmospheric influence of Earth's earliest sulfur cycle. Science 289:756-758.

Frierson, D.M.W., Held, I.M., and Zurita-Gotor, P. (2006) A gray-radiation aquaplanet moist GCM. Part I: static stability and eddy scale. Journal of the Atmospheric Sciences 63:25482566.

Haqq-Misra, J. (2010) A dynamical hierarchy for the general circulation. Ph.D. thesis, The Pennsylvania State University, University Park.

Haqq-Misra, J.D., Domagal-Goldman, S.D., Kasting, P.J., and Kasting, J.F. (2008) A revised, hazy methane greenhouse for the Archean Earth. Astrobiology 8:1127-1137.

Haynes, P.H., McIntyre, M.E., Shepherd, T.G., Marks, C.J., and Shine, K.P. (1991) On the "downward control" of extratropical diabatic circulations by eddy-induced mean zonal forces. Journal of the Atmospheric Sciences 48:651-679.

Heimann, A., Johnson, C.M., Beard, B.L., Valley, J.W., Roden, E.E., Spicuzza, M.J., and Beukes, N.J. (2010) Fe, C, and O isotope compositions of banded iron formation carbonates demonstrate a major role for dissimilatory iron reduction in $\sim 2.5$ Ga marine environments. Earth Planet Sci Lett 294:8-18.
Hendriks, J., Oubrie, A., Castresana, J., Urbani, A., Gemeinhardt, S., and Saraste, M. (2000) Nitric oxide reductases in bacteria. Biochim Biophys Acta 1459:266-273.

Hogg, N.G. (1973) On the stratified Taylor column. J Fluid Mech 58:517-537.

Holland, H.D. (1994) Early Proterozoic atmospheric change. In Early Life on Earth, edited by S. Bengtson, Columbia University Press, New York, pp 237-244.

Holland, H.D. (2002) Volcanic gases, black smokers, and the Great Oxidation Event. Geochim Cosmochim Acta 66:3811-3826.

Holland, H.D. (2006) The oxygenation of the atmosphere and oceans. Philos Trans $R$ Soc Lond B Biol Sci 361:903-915.

Holland, H.D. (2009) Why the atmosphere became oxygenated: a proposal. Geochim Cosmochim Acta 73:5241-5255.

Holton, J.R., Haynes, P.H., McIntyre, M.E., Douglass, A.R., Rood, R.B., and Pfister, L. (1995) Stratosphere-troposphere exchange. Rev Geophys 33:403-439.

Hoskins, B.J., McIntyre, M.E., and Robertson, A.W. (1985) On the use and significance of isentropic potential vorticity maps. Quarterly Journal of the Royal Meteorological Society 111:877-946.

Huppert, H.E. (1975) Some remarks on the initiation of inertial Taylor columns. J Fluid Mech 67:397-412.

Kasting, J.F. (1987) Theoretical constraints on oxygen and carbon dioxide concentrations in the Precambrian atmosphere. Precambrian Res 34:205-229.

Kasting, J.F. (1990) Bolide impacts and the oxidation state of carbon in the Earth's early atmosphere. Orig Life Evol Biosph 20:199-231.

Kasting, J.F. (1992) Proterozoic climates: the effect of changing atmospheric carbon dioxide concentrations. In The Proterozoic Biosphere: A Multidisciplinary Study, edited by J.W. Schopf and C. Klein, Cambridge University Press, Cambridge, pp 165 168.

Kasting, J.F. (1993) Earth's early atmosphere. Science 259:920926.

Kasting, J.F. and Catling, D. (2003) Evolution of a habitable planet. Annu Rev Astron Astrophys 41:429-463.

Kasting, J.F. and Walker, J.C.G. (1981) Limits on oxygen concentration in the prebiological atmosphere and the rate of abiotic fixation of nitrogen. J Geophys Res 86:1147-1158.

Kasting, J.F., Liu, S.C., and Donahue, T.M. (1979) Oxygen levels in the prebiological atmosphere. J Geophys Res 84:3097-3107.

Kasting, J.F., Pollack, J.B., and Crisp, D. (1984) Effects of high $\mathrm{CO}_{2}$ levels on surface temperature and atmospheric oxidation state of the early Earth. J Atmos Chem 1:403-428.

Kasting, J.F., Holland, H.D., and Pinto, J.P. (1985) Oxidant abundances in rainwater and the evolution of atmospheric oxygen. J Geophys Res 90:10497-10510.

Kharecha, P., Kasting, J.F., and Siefert, J.L. (2005) A coupled atmosphere-ecosystem model of the early Archean Earth. Geobiology 3:53-76.

Lamarque, J.-F. and Hess, P.G. (1994) Cross-tropopause mass exchange and potential vorticity budget in a simulated tropopause folding. Journal of the Atmospheric Sciences 51:22462269.

Liang, M.C., Hartman, H., Kopp, R.E., Kirschvink, J.L., and Yung, Y.L. (2006) Production of hydrogen peroxide in the atmosphere of a Snowball Earth and the origin of oxygenic photosynthesis. Proc Natl Acad Sci USA 103:18896-18899.

Martin, R.V., Chance, K., Jacob, D.J., Kurosu, T.P., Spurr, R.J.D., Bucsela, E., Gleason, J.F., Palmer, P.I., Bey, I., and Fiore, A.M. (2002) An improved retrieval of tropospheric nitrogen dioxide from GOME. J Geophys Res 107, doi: 10.1029/2001JD001027. 
McIntyre, M.E. and Palmer, T.N. (1983) Breaking planetary waves in the stratosphere. Nature 305:593-600.

McKay, C.P. and Hartman, H. (1991) Hydrogen-peroxide and the evolution of oxygenic photosynthesis. Orig Life Evol Biosph 21:157-163.

Mizuta, R. and Yoden, S. (2001) Chaotic mixing and transport barriers in an idealized stratospheric polar vortex. Journal of the Atmospheric Sciences 58:2616-2629.

Ono, S., Eigenbrode, J.L. Pavlov, A.A., Kharecha, P., Rumble, D., III, Kasting, J.F., and Freeman, K.H. (2003) New insights into Archean sulfur cycle from mass-independent sulfur isotope records. Earth Planet Sci Lett 213:15-30.

Pavlov, A.A., Brown, L.L., and Kasting, J.F. (2001) UV shielding of $\mathrm{NH}_{3}$ and $\mathrm{O}_{2}$ by organic hazes in the Archean atmosphere. $J$ Geophys Res 106:23267-23287.

Pereira, M.M., Santana, M., and Teixeira, M. (2001) A novel scenario for the evolution of haem-copper oxygen reductases. Biochim Biophys Acta 1505:185-208.

Randel, W.J., Gille, J.C., Roche, A.E., Kumer, J.B., Mergenthaler, J.L., Waters, J.W., Fishbein, E.F., and Lahoz, W.A. (1993) Stratospheric transport from the tropics to middle latitudes by planetary-wave mixing. Nature 365:533-535.

Reed, R.J. (1955) A study of a characteristic type of upper-level frontogenesis. Journal of Meteorology 12:226-237.

Rosing, M.T., Bird, D.K., Sleep, N.H., and Bjerrum, C.J. (2010) No climate paradox under the faint early Sun. Nature 464:744747.

Rye, R., Kuo, P.H., and Holland, H.D. (1995) Atmospheric carbon dioxide concentrations before 2.2 billion years ago. Nature 378:603-605.

Sander, R. (2009) Henry's Law constants. In NIST Chemistry WebBook, NIST Standard Reference Database Number 69, edited by P.J. Lindstrom and W.G. Mallards, National Institute of Standards and Technology, Gaithersburg, MD. Available online at http://webbook.nist.gov.

Schopf, J.W. (1975) Precambrian paleobiology: problems and perspectives. Annu Rev Earth Planet Sci 3:213-249.

Schwartz, R.M. and Dayhoff, M.O. (1978) Origins of prokaryotes, eukaryotes, mitochondria, and chloroplasts. Science 199:395-403.

Segura, A., Meadows, V., Kasting, J., Crisp, D., and Cohen, M. (2007) Abiotic formation of $\mathrm{O}_{2}$ and $\mathrm{O}_{3}$ in high- $\mathrm{CO}_{2}$ terrestrial atmospheres. Astron Astrophys 472:665-680.

Shapiro, M.A. (1980) Turbulent mixing within tropopause folds as a mechanism for the exchange of chemical constituents between the stratosphere and troposphere. Journal of the Atmospheric Sciences 37:994-1004.

Sheldon, N.D. (2006) Precambrian paleosols and atmospheric $\mathrm{CO}_{2}$ levels. Precambrian Res 147:148-155.
Sleep, N.H. and Zahnle, K. (2001) Carbon dioxide cycling and implications for climate on ancient Earth. J Geophys Res 106:1373-1399.

Stolper, D.A., Revsbech, N.P., and Canfield, D.E. (2010) Aerobic growth at nanomolar oxygen concentrations. Proc Natl Acad Sci USA 107:18755-18760.

Towe, K.M. (1978) Early Precambrian oxygen: a case against photosynthesis. Nature 274:657-661.

Towe, K.M. (1988) Biochemical arguments for early $\mathrm{O}_{2}$. In Molecular Evolution and the Fossil Record, edited by T.W. Broadheads, University of Tennesee, Knoxville, pp 114-129.

Towe, K.M. (1990) Aerobic respiration in the Archaean? Nature 348:54-56.

Towe, K.M. (1996) Environmental oxygen conditions during the origin and early evolution of life. Adv Space Res 18:7-15.

von Paris, P., Rauer, H., Grenfell, J.L., Patzer, B., Hedelt, P., Stracke, B., Trautmann, T., and Schreier, F. (2008) Warming the early earth: $\mathrm{CO}_{2}$ reconsidered. Planet Space Sci 56:12441259.

Walker, J.C.G. (1977) Evolution of the Atmosphere, MacMillan, New York.

Walker, J.C.G. (1985) Carbon dioxide on the early Earth. Orig Life Evol Biosph 16:117-127.

Walker, J.C.G. and Zahnle, K.J. (1986) Lunar nodal tide and distance to the Moon during the Precambrian. Nature 320:600602.

Waugh, D.W. (1993) Subtropical stratospheric mixing linked to disturbances in the polar vortices. Nature 365:535-537.

Wei, M.-Y. (1987) A new formulation of the exchange of mass and trace constituents between the stratosphere and troposphere. Journal of the Atmospheric Sciences 44:3079-3086.

Williams, G.E. (2000) Geological constraints on the Precambrian history of Earth's rotation and the Moon's orbit. Rev Geophys 38:37-59.

Wolf, E.T. and Toon, O.B. (2010) Fractal organic hazes provided an ultraviolet shield for early Earth. Science 328:12661268.
Address correspondence to: Jacob Haqq-Misra 407 Walker Building

The Pennsylvania State University University Park, PA 16802

E-mail: misra@meteo.psu.edu

Submitted 12 November 2010 Accepted 19 February 2011 